Original Research Article

\title{
Study of prevalence and prescribing trends in infectious diseases: as a teaching tool for MBBS $2^{\text {nd }}$ professional students
}

\author{
Mirza A. Beg*, Shakti B. Dutta, Shalu Bawa, Amanjot Kaur, Subhash Vishal
}

\begin{abstract}
Department of Pharmacology, Shri Guru Ram Rai Institute of Medical and Health Sciences, Patel Nagar, Dehradun, Uttarakhand, India
\end{abstract}

Received: 10 April 2017
Accepted: 02 May 2017

*Correspondence to:

Dr. Mirza A. Beg,

Email: mabeg1997@gmail.com

Copyright: (C) the author(s), publisher and licensee Medip Academy. This is an openaccess article distributed under the terms of the Creative Commons Attribution NonCommercial License, which permits unrestricted noncommercial use, distribution, and reproduction in any medium, provided the original work is properly cited.

\begin{abstract}
Background: Irrational prescription of drugs is a common occurrence in clinical practice. Introduction of clinical pharmacology at the undergraduate level as an integral part of rational therapeutics is the need of hour. The present drug utilization study, prevalence and prescribing pattern in infectious diseases in a tertiary care teaching hospital was carried out to teach clinical pharmacology to 2nd professional MBBS students, to sensitize and promote rational prescribing.
\end{abstract}

Methods: A total of 621 prescriptions were collected by $2^{\text {nd }}$ professional MBBS students at Shri Guru Ram Rai Institute of Medical and Health Sciences, Dehradun. Prescriptions were analyzed on various parameters, using WHO drug use indicators.

Results: A total of 621 prescriptions were analyzed. 477 (76.81\%) were males and $144(23.19 \%)$ were females. Majority of patients 357 (57.49\%) were 16-60 years' age group. The infectious diseases prevalence was $153(24.63 \%)$ enteric fever, $132(21.26 \%)$ hepatitis, $111(17.87 \%)$ pyrexia of unknown origin, 90 $(14.49 \%)$ cellulitis, $135(21.74 \%)$ belongs to miscellaneous category respectively. A total of 4446 drugs were prescribed, which includes antibiotics $2025(45.55 \%)$, multivitamins $969(21.79 \%)$, antacids $699(15.72 \%)$, analgesics $408(9.18 \%)$, antiemetic $273(6.14 \%)$ and antiepileptic $72(1.62 \%)$ respectively. $3096(69.64 \%)$ oral, 1350 (30.36\%) injectable and 786 (17.68\%) fixed dose combinations (FDCs) were prescribed. 3.26 antibiotics and 7.15 drugs per prescription were prescribed. $2622(58.97 \%)$ drugs were prescribed from national essential medicine list 2015. 100\% drugs were prescribed by brand names.

Conclusions: The prescriptions revealed polypharmacy. This study can help to provide feedback to the prescribers, thereby increase in awareness and improve patient care by rational utilization of drugs.

Keywords: Clinical pharmacology, Infectious diseases, Prescribing pattern

\section{INTRODUCTION}

Prescribing practices are a reflection of health professional's abilities to discriminate among the various choices of drugs and determine the ones that will most benefit their patient. Nowadays drug utilization studies are used as potential tool in the evaluation of health care systems.

Despite a century of often successful prevention and control efforts, Infectious diseases remain an important global problem in public health, causing over 13 million deaths each year. Enteric fever is an endemic disease and a serious public health problem in India. Changes in society, technology and the microorganisms themselves are contributing to the emergence of new diseases, the reemergence of diseases once controlled, and to the development of antimicrobial resistance. ${ }^{1}$ The effective control of infectious diseases in the new millennium will require effective public health infrastructures that will rapidly recognize and respond to them and will prevent emerging problems. ${ }^{2}$ But it is important to realize that the inappropriate use of drugs represent a potential hazard to the patients. The aim is to facilitate the rational use in population which implies to the prescription of a welldocumented drug in an optimal dose and at a right indication. ${ }^{3}$ This Drug Utilization study in Infectious 
Diseases was conducted by the Department of Pharmacology in the Hospital ward at Shri Guru Ram Rai Institute of Medical and Health Sciences (SGRRIM and HS) Dehradun, as a part of teaching clinical pharmacology to undergraduate (MBBS) $2^{\text {nd }}$ professional students.

\section{METHODS}

The retrospective study was conducted by Pharmacology department in SGRRIM and HS, Dehradun. A total of 621 prescriptions were collected by $2^{\text {nd }}$ professional MBBS students and randomly evaluated. Approval of the institutional ethics committee was obtained prior to commencement of the study. The data was analyzed in the department for assessing the rationality in prescription. WHO drug prescribing indicators like, drug formulations, average number of drugs per prescription, fixed dose combinations (FDCs), percentage of drugs prescribed by brand names, percentage of drugs from NLEM 2015.

\section{RESULTS}

A total of 621 prescriptions were analyzed. Male were $477(76.81 \%)$ and $144(23.19 \%)$ were females. Majority $357(57.49 \%)$ of the patients were 16-60 years' age group (Table 1).

Table 1: Demographic data.

\begin{tabular}{|ll|}
\hline Age wise distribution (207) & Number (\%) \\
\hline $0-15$ & $159(25.60 \%)$ \\
\hline $16-30$ & $102(16.43 \%)$ \\
\hline $31-45$ & $198(31.88 \%)$ \\
\hline $46-60$ & $57(9.18 \%)$ \\
\hline$>60$ & $105(16.90 \%)$ \\
\hline
\end{tabular}

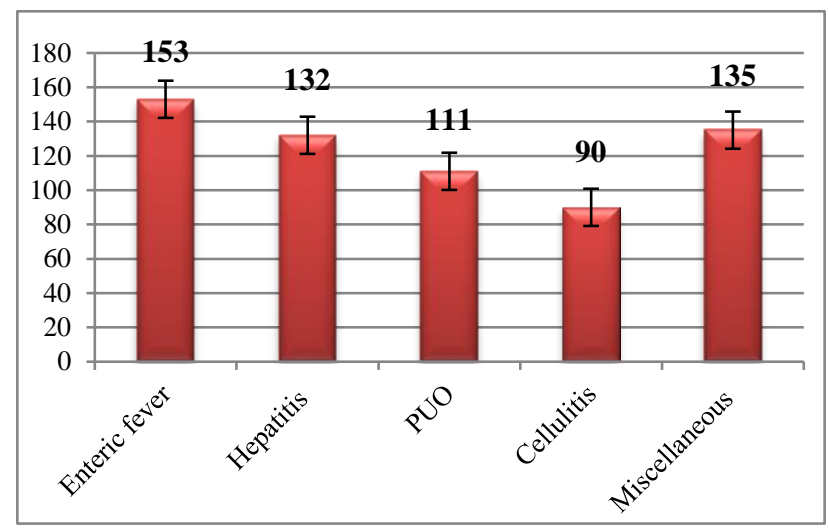

Figure 1: Disease prevalence pattern.

Disease pattern reported in our study, were enteric fever 153 (24.63\%), hepatitis $132(21.26 \%)$, Pyrexia of unknown origin 111(17.87\%), Cellulitis 90 (14.49\%) and miscellaneous category (which includes appendicitis, infected hernia, abscess, skin and soft tissue infections and wound infection) were $135(21.74 \%)$ respectively (Figure 1).

A total of 4446 drugs were prescribed, which includes antibiotics $2025 \quad(45.55 \% \%)$, multivitamins 969 (21.79\%), antacids 699 (15.72\%), analgesics 408 $(9.18 \%)$, antiemetic $273(6.14 \%)$ and antiepileptic 72 (1.62\%) respectively (Figure 2 ).

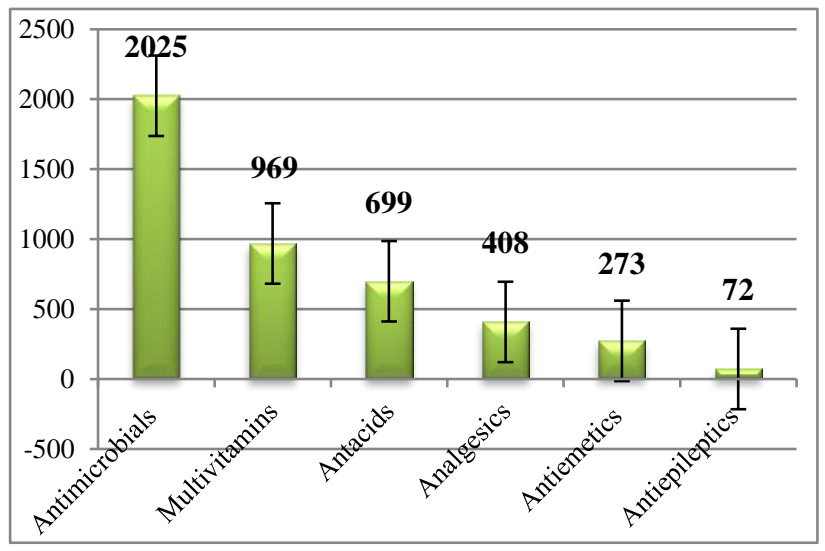

Figure 2: Drugs prescribed from different drug groups.

Most frequently prescribed antibiotic was cefoperazone plus sulbactam fixed dose combination 420 (20.74\%), levofloxacin 348 (17.19\%), amoxicillin plus clavulinic acid combination 294 (14.52\%) respectively (Figure 3).

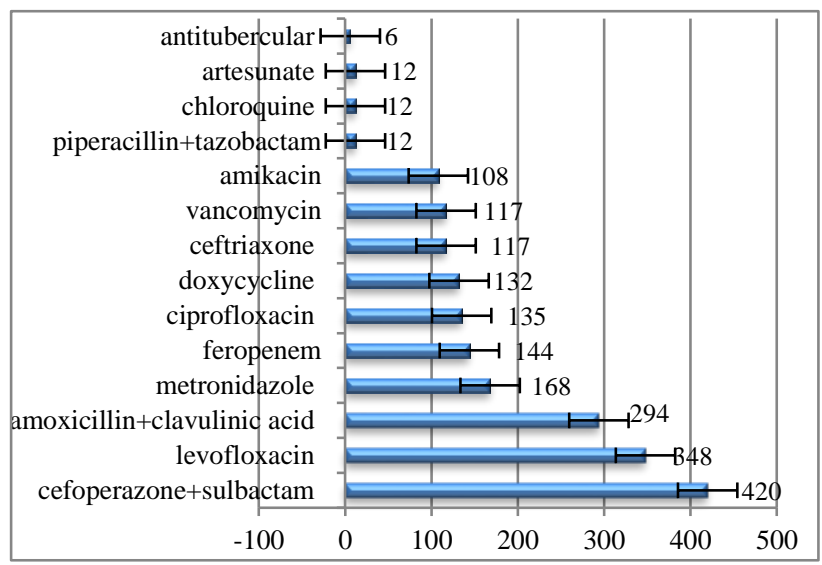

Figure 3: Antimicrobials prescribed.

Ranitidine 237(33.90\%) and pantoprazole 237 (33.90\%) as antacids, paracetamol $213(52.20 \%)$ as analgesic and ondansetron $156(57.14 \%)$ as antiemetic were frequently prescribed. $3096(69.64 \%)$ of the drug formulations were oral and $1350(30.36 \%)$ were injectable (Figure 4).

$786(17.68 \%)$ FDCs were prescribed, cefoperazone plus sulbactam being the most commonly prescribed combination (Table 2 and 3). 3.26 antibiotic and 7.24 drugs were prescribed per prescription. 4446 (100\%) drugs with brand name and $2622(58.97 \%)$ drugs from 
national list of essential medicines 2015 were prescribed (Table 3).

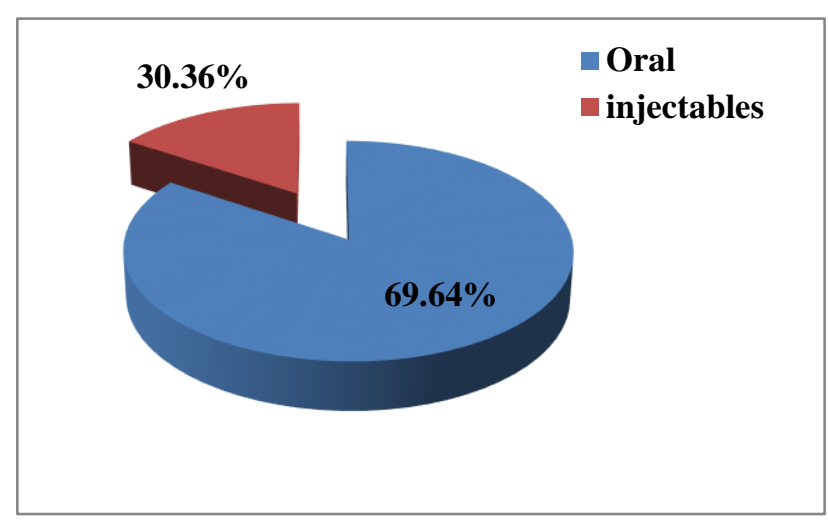

Figure 4: Drug formulations.

Table 2: Fixed dose combinations.

\begin{tabular}{|ll|}
\hline FDCs & Number (\%) \\
\hline Inj Cefoperazone +Sulbactam & $420(53.44 \%)$ \\
\hline Tab Amoxicillin+Clavulinic Acid & $294(37.40 \%)$ \\
\hline Tab Domperidon+Pantoprazole & $60(7.63 \%)$ \\
\hline Inj Piperacillin+Tazobactam & $12(1.53 \%)$ \\
\hline
\end{tabular}

Table 3: Other parameters.

\begin{tabular}{|ll|}
\hline Parameters & Number (\%) \\
\hline Fixed dose combinations (FDCs) & $786(17.68 \%)$ \\
\hline Drugs per prescription & 7.15 \\
\hline Antibiotics per prescription & 3.26 \\
\hline $\begin{array}{l}\text { Drugs from national list of essential } \\
\text { medicines }\end{array}$ & $2622(58.97 \%)$ \\
\hline Drugs prescribed by brand names & $100 \%$ \\
\hline
\end{tabular}

\section{DISCUSSION}

The present study was an attempt to develop clinical skills in MBBS $2^{\text {nd }}$ professional students about the rational prescribing. In our study an attempt has been made to educate the undergraduate students about the significance of drug utilization study. Drug utilization study is an inexpensive, flexible and simple method to assess the utilization pattern of the drugs. ${ }^{4}$ Mere theoretical teaching is not enough and the students must be taught the certain basic skills which will be a core component of practicing rational therapeutics.

In India the range and burden of infectious diseases is enormous, although it has decreased as a result of overall socioeconomic progress and use of vaccines and antimicrobials but still a major health care burden in India. $^{5}$ The present study showed more number of infectious diseases in males $(76.81 \%)$ as compared to females $(23.19 \%)$, which is comparable to the study by Revathi R et al. ${ }^{4}$ In present study 16-60 years of age group was the major affected age group with infectious diseases, which is in relation to the previous study in which the most commonly presenting age group of infectious diseases was 13-59 years. ${ }^{4}$ Enteric Fever $24.63 \%$ was the common infectious disease in present study, which is comparable to the study by Revathi $\mathrm{R}$ et al. ${ }^{4}$ Enteric fever remains an important and persistent public health problem in developing nations including India. Antimicrobial agents $(45.55 \%)$ were the most frequently prescribed drug in our study, which is similar to the a previous study in which prescribing trends in a teaching hospital were assessed and percentage of prescriptions containing antimicrobials were high, but in contrast to another study of prescribing trends has depicted the $22.76 \%$ of the prescriptions were of antimicrobials. ${ }^{6,7}$ Most commonly prescribed antibiotics were cefaperazone plus sulbactam fixed dose combination, which is in comparison to earlier study where most commonly prescribed antibiotic were cephalosporins. ${ }^{8} 100 \%$ of the drugs were prescribed by a brand name which is in comparison to the previous study where $98 \%$ drugs were prescribed by brand names and only $2 \%$ were by generic names. ${ }^{9}$ It needs awareness that the generic names in prescriptions eliminate the chance of duplication of the drug products and also reduce the cost of the drugs/prescriptions. ${ }^{10}$ Percentage of oral drug formulations was high $(69.64 \%)$ which is in contrast to the study by Sarkar C et al where the percentage of injectable drugs were high 54.52\%. ${ }^{11} 3.26$ antibiotics were prescribed per prescription, which in contrast to the study by Meher BR et al where 1.83 antibiotics were prescribed per prescription. ${ }^{12} 7.15$ drugs were prescribed per prescription, which is higher than the previous study by Gupta $\mathrm{R}$ et al where 2.35 drugs were prescribed per prescription. ${ }^{13}$ The FDCs in the present study were $17.68 \%$, which is lower than the previous study in which $45.66 \%$ FDCs were prescribed. ${ }^{13}$ Polypharmacy observed in present study.

Principal target is to promote the rational prescribing of drugs with the aim to develop clinical skills among students. Training of students through such research gives an orientation to them which have a bearing on their further training in final professional and internship. Appropriate use of drugs is one essential element in achieving quality of health and medical care for patients and the community as a whole. ${ }^{14}$

Such kind of studies needs to be conducted to assess that inappropriate use of drugs represent a potential hazard to patients. The disadvantages of irrational prescriptions such as increase possibilities of adverse drug reactions, drug-drug interactions and hazards of polypharmacy that is observed in the present study were discussed with the students, the future prescribers.

Funding: No funding sources Conflict of interest: None declared

Ethical approval: The study was approved by the Institutional Ethics Committee 


\section{REFERENCES}

1. Nandi PL, Chan JNF, Chan CPK, Chan P, Chan LPK. Undergraduate medical education: comparison of problem-based learning and conventional teaching. HKMJ. 2000;6:301-6.

2. Gitanjali B, Shashindran $\mathrm{CH}$. Curriculum in clinical pharmacology for medical undergraduates of India. Indian J Pharmacol. 2006;38:108-14.

3. Kaushal S, Chopra SC, Arora S. Modifications in the undergraduate MBBS pharmacology practical curriculum: The DMCH model. Indian J Pharmacol. 2007;39(1):57-9.

4. Revrathi R, Gopalkrishnan S. Study of notifiable infectious diseases reported to a tertiary care teaching hospital in Kancheepuram, District of Tamil Nadu. Nat. J. Res. Com. Med. 2014;41-6.

5. John TJ, Dandona L, Sharma VP, Kankar M. Continuing challenge of infectious diseases in India. Lancet. 2011;13:252-69.

6. Ghosh R, Neogi JN, Srivastva BS, Sen P. Prescribing trends in a teaching hospital in Nepal. JNMA. 2003;42:340-49.

7. Bhattacharya A, Gupta $H$, Dewangan MK. Prescribing pattern study of drugs used in a tertiary hospitals of the Bilaspur region. Asian $\mathbf{J}$ of Pharmaceutical and Clinical Research. 2012;5:73-6.

8. Biswas M, Roy DN, Rahman M, Islam M, Parvez M, Haque U, Shahriar AAE et al. Prescribing trends of antibiotics for outpatients in Bangladesh: A cross sectional health survey conducted in three districts. IJPSR. 2014;19:669-75.

9. Ansari KU, Singh S, Pandey RC. Evaluation of prescribing pattern of doctors for rational drug therapy. Indian J Pharmacol. 1998;30:43-6.

10. Benet LZ. Principles of prescription order writing and patient compliance instructions. In: Hardman JG, Limbard LE, Molinoff PB, Ruddon RW, Gilman AG (editors). Goodman and Gilman's the pharmacological basis of Therapeutics, $9^{\text {th }}$ Ed. New York: McGraw Hill; 1996:1697-1706.

11. Sarkar C, Das B. Prescribing trends in a teaching hospital in western Nepal. JNGMC. 2002;2:4-7.

12. Meher BR, Mukharjee D, Dayshankar U. A study on antibiotic utilization in a general medicine ward of a tertiary care teaching hospital. 2014;6(7):1847-49.

13. Gupta R, Marko JL. Drug prescription pattern of outpatients in a tertiary care teaching hospital in central India. International $\mathrm{J}$ of Bioassays. 2014;3(12):3566-68.

14. Ola A, Azza A, Mahalli El, Salem AM, Elkahky AA. WHO/INRUD drug use indicators at primary healthcare centres in Alexandria, Egypt. J of Taibah university medical sciences. 2014;9(1):54-64.

Cite this article as: Beg MA, Dutta SB, Bawa S, Kaur A, Vishal S. Study of prevalence and prescribing trends in infectious diseases: as a teaching tool for MBBS 2nd professional students. Int J Basic Clin Pharmacol 2017;6:1441-4. 